\title{
Screening of pepper accessions for resistance against two thrips species (Frankliniella occidentalis and Thrips parvispinus)
}

\author{
Awang Maharijaya • Ben Vosman • Greet Steenhuis-Broers • \\ Asep Harpenas - Agus Purwito - Richard G. F. Visser • \\ Roeland E. Voorrips
}

Received: 27 August 2010/Accepted: 27 September 2010/Published online: 15 October 2010

(C) The Author(s) 2010. This article is published with open access at Springerlink.com

\begin{abstract}
Thrips are damaging pests in pepper worldwide. They can cause damage directly by feeding on leaves, fruits or flowers, and also indirectly by transferring viruses, especially tomato spotted wilt virus (TSWV). Although thrips are among the most damaging pests in pepper, until now there is no commercial variety with a useful level of resistance to thrips. This is at least partly due to the lack of knowledge on resistance levels in pepper germplasm of QTLs and/or genes for resistance, and of information about resistance mechanisms to thrips in pepper. This paper describes our research aimed at developing practical and reliable screening methods for thrips resistance in pepper and at identifying pepper accessions showing a strong resistance to thrips. Thirty-two pepper accessions from four species of pepper (Capsicum аппиит,
\end{abstract}

A. Maharijaya - B. Vosman · G. Steenhuis-Broers ·

R. G. F. Visser · R. E. Voorrips $(\square)$

Wageningen UR Plant Breeding, Wageningen University and Research Center, P.O. Box 16, 6700 Wageningen,

The Netherlands

e-mail: roeland.voorrips@wur.nl

A. Maharijaya $\cdot$ A. Purwito

Bogor Agricultural University, Jalan Raya Darmaga,

16680 Bogor, Indonesia

\section{A. Harpenas}

East-West Seeds, P.O. Box 1, 41181 Campaka,

Purwakarta, Indonesia
C. baccatum, $C$. chinense and $C$. frutescens) and two species of thrips (Frankliniella occidentalis and Thrips parvispinus) were used in this study. Our results indicate that the laboratory based leaf disc test and the detached leaf test can be used as reliable screening methods for thrips resistance in pepper. We observed a large variation for resistance to thrips in Capsicum that can be exploited in breeding programs.

Keywords Capsicum - In vitro test - Multiple resistance $\cdot$ Insect resistance

\section{Introduction}

Pepper (Capsicum spp.) is one of the most widely grown vegetables in the world and faces problems from thrips attack (Grubben and Denton 2004; Siemonsma and Piluek 1994). Thrips can cause damage on pepper directly by feeding on leaves, fruits or flowers. Feeding injury from thrips on leaves may affect leaf size, affect carbon allocation in the plant (Shipp et al. 1998; Welter et al. 1990) and reduce photosynthetic capacity (Tommasini and Maini 1995). Thrips also cause indirect damage by transmitting plant viruses of the Tospovirus, Ilarvirus, Carmovirus, Sobemovirus, and Machlomovirus genera (Jones 2005). One of the most important viruses transmitted by thrips in pepper is tomato spotted wilt virus (TSWV) (Ulman et al. 1992). 
At least 16 thrips species have been reported to occur on Capsicum (Capinera 2001; Talekar 1991). Frankliniella occidentalis is the most common thrips species on Capsicum in Europe (Tommasini and Maini 1995), while Thrips parvispinus is the main species in Indonesia, Malaysia, the Philippines, Thailand and Taiwan (Reyes 1994). On Java, Indonesia, T. parvispinus has been reported as a major pest of Capsicum (Prabaningrum and Suhardjono 2007; Vos and Frinking 1998).

Thrips are difficult to control because of their polyphagous nature and their high reproduction rate (Weintraub 2007). At moderate temperatures $\left(20-25^{\circ} \mathrm{C}\right), F$. occidentalis takes about $2-3$ weeks to complete its life cycle, but at $30^{\circ} \mathrm{C}$ it may take less than 10 days (Tommasini and Maini 1995). Another factor that contributes to a rapid development of thrips is that their reproduction is facultatively parthenogenic (Brodsgaard 1989).

Controlling thrips using pesticides is difficult and not very effective because of their cryptic habit. They prefer enclosed areas such as buds, flowers, under the calyx of the fruits and in newly opening leaves (Jensen 2000; Weintraub 2007). In addition, they develop resistance to insecticides rapidly. Resistance to insecticides of three major classes: organophosphates, carbamates and pyrethroids has been reported (Bielza 2008; Herron and James 2005; Herron 2005; Jensen 2000). Nevertheless, pesticides are still widely used to control thrips. However, there is an increasing public demand for reduction of pesticide use and withdrawal of certain chemical compounds because of their harmful effects on growers, consumers and the environment (Dik et al. 2000).

As an alternative to the use of insecticides, integrated pest management (IPM) has been implemented in pepper (Weintraub 2007). However, solely relying on IPM is difficult when no varieties are available that are at least moderately resistant to thrips. In fact, the most effective way to eliminate the thrips problem would be the use of highly resistant varieties. Resistance to thrips may also delay and reduce the transmission of viruses as shown by Maris et al. (2003) for TSWV. However, resistant pepper varieties do not exist and are unlikely to become available soon.

Studies on thrips resistance in pepper are needed to support breeding programs aimed at developing thrips resistant varieties. As a first step pepper accessions with an effective level of resistance to thrips need to be identified. This requires reliable and efficient methods to assess the resistance of accessions. Our study therefore has two objectives. The first objective is to develop and evaluate efficient phenotyping methods, which are needed for the screening of pepper lines and accessions. If such methods are to be of use in research and breeding they must be easy to conduct, accurate, reproducible, requiring little space, time, and energy. Several test methods have been described in the past including a leaf disc assay for thrips resistance in cucumber (Kogel et al. 1997), a detached leaf test for Helicoverpa armigera resistance in pea (Sharma et al. 2005) and a screen cage test for aphids resistance in sweet pepper (Pineda et al. 2007).

The second objective of our study is to identify accessions with different levels of thrips resistance (including highly resistant accessions) that can be used for studies aimed at elucidating the genetics of resistance against thrips.

\section{Materials and methods}

Plant material

Pepper accessions with possible resistance to thrips were selected on the basis of available literature (Fery and Schalk 1991; Maris et al. 2003) and supplemented with other accessions of various species and geographic origins; they were obtained from the Center of Genetic Resources, the Netherlands at Wageningen, the Netherlands; from Plant Research International, Wageningen and from PT East West Seed Indonesia (EWINDO), Purwakarta, Indonesia. In total, 32 pepper accessions from four species: C. annuum, C. chinense, C. baccatum and C. frutescens were used (Table 1).

\section{Thrips species}

Two species of thrips were used, Frankliniella occidentalis and Thrips parvispinus. Frankliniella occidentalis was selected as it is the most prevalent thrips species in European pepper cultivation (Tommasini and Maini 1995), while T. parvispinus was selected as representative of Asian thrips (Prabaningrum and Suhardjono 2007; Reyes 1994; Vos and Frinking 1998). 


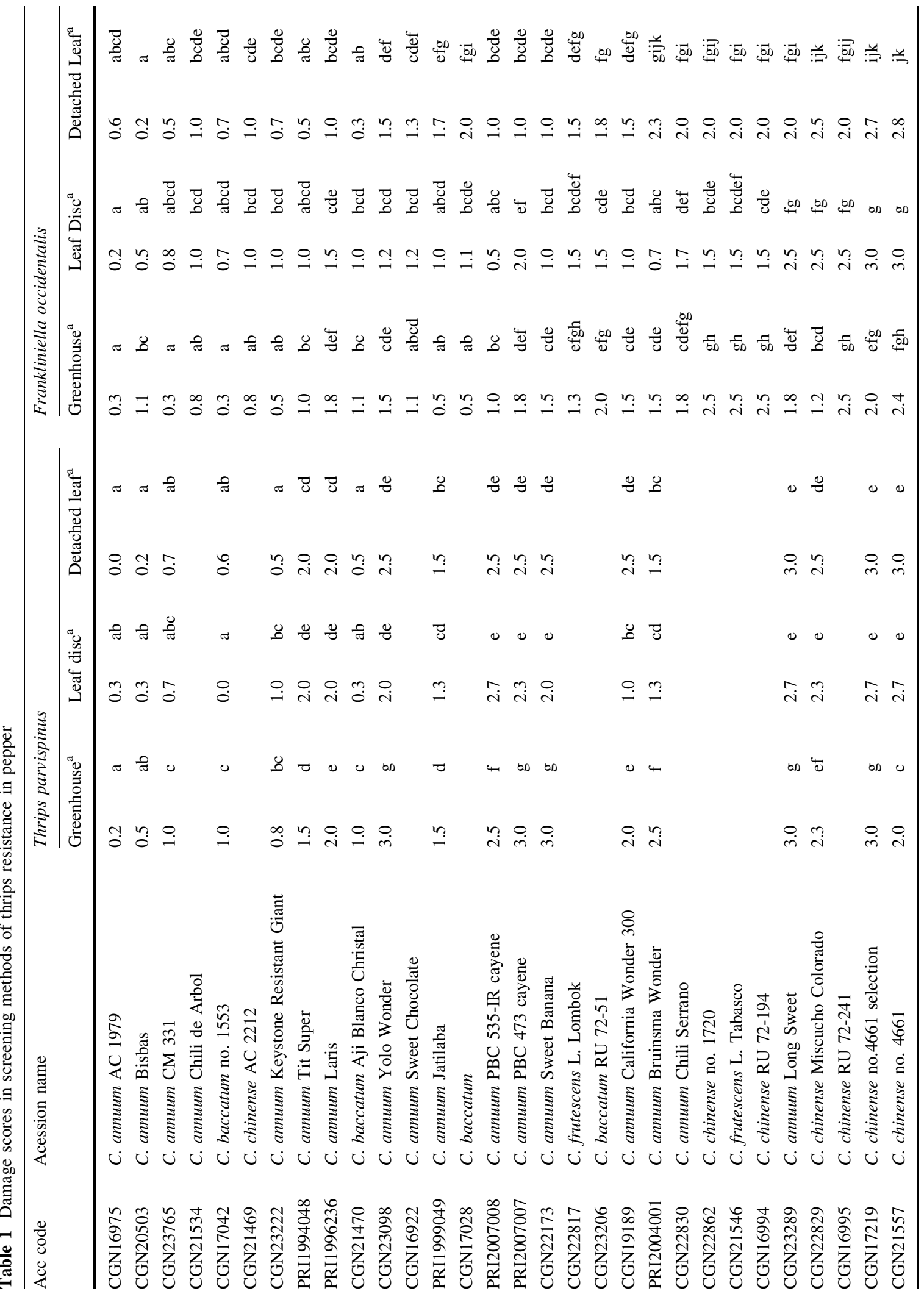


Screening methods

Greenhouse tests

Pepper accessions were grown on raised beds in a screenhouse of EWINDO at Purwakarta, West Java, Indonesia. Seedlings were raised under insect free conditions in a seedling bed and transplanted 6 weeks after germination. Six plants per accession were planted in a plot, with two replications in a randomized block design. Plants were spaced $75 \mathrm{~cm}$ between rows and $45 \mathrm{~cm}$ between plants in a row. Pepper plants were grown according to standard screenhouse pepper cultivation techniques (Rossel and Ferguson 1979). Thrips infestation was spontaneous as expected, starting from 2 weeks after transplantation. Thrips were identified as T. parvispinus. Four weeks after the first symptoms occurred (when the most susceptible accessions were very severely affected), peppers were rated for damage using a relative scale from 0 (no damage) to 3 (severe damage, i.e. strongly curled leaves, silvering and black spots). In the Netherlands the plant material was grown at $25^{\circ} \mathrm{C}, 16 / 8 \mathrm{~h}$ day/night cycle under standard glasshouse conditions at Wageningen University and Research Centre, Wageningen. Four plants per accession were planted in a plot, with two replications in a randomized block design. After a natural thrips ( $F$. occidentalis) infestation, plant were rated using a relative scale from 0 (no damage) to 3 (severely curled leaves) 7 weeks after transplantation.

\section{Leaf disc tests}

T. parvispinus were collected from a pepper field at Purwakarta, Indonesia, while $F$. occidentalis were reared on susceptible Chrysanthemum cultivar Spoetnik (Fides, De Lier, the Netherlands) in an insect greenhouse at $25^{\circ} \mathrm{C}$ and $70 \%$ relative humidity (Koschier et al. 2000). Adult female thrips were starved for $24 \mathrm{~h}$ in a cage with only water (Murai and Antoon 2001). Leaf discs (4 cm in diameter) were taken from fully opened leaves using a leaf punch and placed in Petri dishes on water agar ( $15 \mathrm{~g} / \mathrm{l}$ agar) with the lower (abaxial) side upward. Ten starved female adult thrips were placed on each leaf disc using a wet brush. Dishes were closed using either silk-like textile (in Indonesia) or air-permeable plastic (in the Netherlands) to prevent thrips from escaping and 
placed in a climate room at $24^{\circ} \mathrm{C}, 16 \mathrm{~h}$ light, $70 \%$ $\mathrm{RH}$. There were six replicates for each accession. The extent of 'silver damage' and destruction by thrips feeding, oviposition and secretion were rated together using a relative scale from 0 (no damage) to 3 (severe damage) 2 days after inoculation.

\section{Detached leaf tests}

The detached leaf tests were performed as the leaf disc test, except that intact leaves from each accession were placed with their petioles in wet Oasis ${ }^{\circledR}(2 \times 5 \times$ $4 \mathrm{~cm}$ ) and were put in a jar. Jars were closed using silklike textile (in Indonesia) or air-permeable plastic (in The Netherlands) and placed in a climate room at $24^{\circ} \mathrm{C}, 16 \mathrm{~h}$ light, $70 \% \mathrm{RH}$. There were six replicates for each accession. The extent of 'silver damage' and destruction by thrips feeding, oviposition and secretion were rated together using a relative scale from 0 (no damage) to 3 (severe damage) 2 days after inoculation.

\section{Heritability estimation}

Heritability values of each test were calculated using variance components estimated from analysis of variance using the following formulas: Genetic variance $\left(\sigma_{\mathrm{g}}^{2}\right)=($ Accession mean square-Residual mean square $) / \mathrm{r}$; Phenotypic variance $\left(\sigma_{\mathrm{p}}^{2}\right)=\sigma_{\mathrm{g}}^{2}+\sigma_{\mathrm{e}}^{2}$; Heritability $\left(h^{2}\right)=\sigma_{\mathrm{g}}^{2} / \sigma_{\mathrm{p}}^{2}$; where $\mathrm{r}$ is the number of replicates.

\section{Statistical analysis}

Accession effects were tested using Kruskal-Wallis tests; for pairwise comparisons between accessions Wilcoxon tests were used. Spearman rank correlations were calculated to compare the different test methods.

Grouping accessions with a similar pattern of resistance

Accessions were clustered based on the results of the three test methods for each thrips species, using hierarchical clustering according to the minimum variance method (Ward 1963) and multiscale bootstrap resampling analysis (Suzuki and Shimodaira 2006). Calculations and construction of the dendrograms were performed using the $\mathrm{R}$ software package Pvclust (http://www.r-project.org/).

\section{Results}

Greenhouse tests

In the screenhouse and greenhouse tests we observed leaf deformation, curling and silvering mostly at the abaxial side of the leaves (Fig. 1a, b). Those symptoms occurred together, i.e. accessions with much leaf deformation also showed much curling and silvering, and vice versa. Thrips were also found inside the flowers and in young leaf buds.

All symptoms started to occur 3 weeks after transplanting. The damage scores were recorded 7 weeks after transplanting, when the most susceptible accessions were very severely affected. In the screenhouse test with $T$. parvispinus, the seven most severely damaged accessions did not differ significantly from
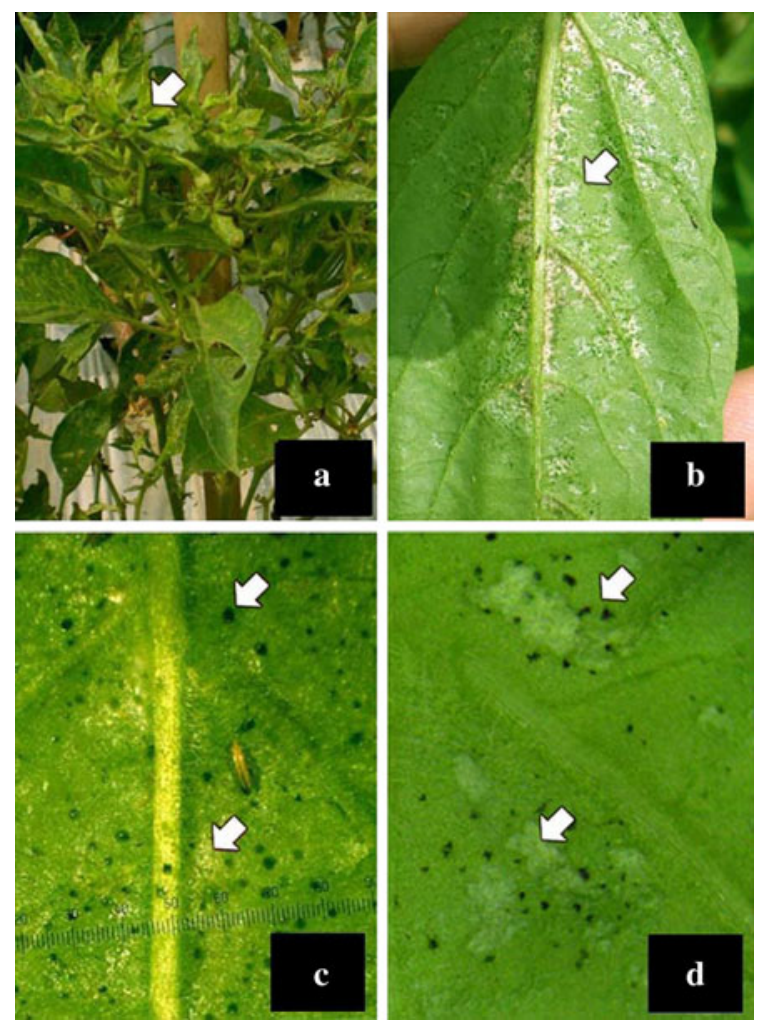

Fig. 1 Damage caused by thrips in different screening methods. a leaf curling and deformation in the greenhouse test (indicated by arrow), b silvering damage caused by thrips feeding and black spots caused by fecal material in the greenhouse test (indicated by arrow), c silver damage caused by thrips feeding and black spots caused by fecal material in the leaf disc test (indicated by arrows), $\mathbf{d}$ idem, in the detached leaf test 
each other, while C. annuum 'AC 1979' and 'Bisbas' were the most resistant in this test (Table 1). In the greenhouse test with $F$. occidentalis, the seven most damaged accessions did not differ significantly from each other, nor did the nine least damaged accessions (Table 1).

\section{Leaf disc tests}

Both T. parvispinus and F. occidentalis produced silvering damage and black spots (Fig. 1c). Symptoms appeared 2 days after inoculation on the abaxial side. Based on the microscopic observation $(100 \times)$, we could not find any differences between the type of damage caused by $T$. parvispinus and F. occidentalis in our leaf disc experiments.

The mean damage scores observed in leaf disc test with $T$. parvispinus ranged from 0.0 to 2.7 . The twelve most damaged accessions did not differ significantly from each other, nor did the five least affected accessions (Table 1). In the tests with $F$. occidentalis the mean damage scores ranged from 0.2 to 3.0. In this case within the seven most damaged and the eight least damaged accessions no significant differences were observed (Table 1).

Detached leaf test

The damage in the detached leaf tests at 2 days after inoculation was very similar to that in the leaf disc tests (Fig. 1c, d). All damage was found at the abaxial side of the leaves. Also in this test T. parvispinus and $F$. occidentalis produced identical symptoms.

The mean damage scores in the detached leaf test with $T$. parvispinus ranged from 0.0 to 3.0. The ten most damaged accessions did not differ significantly from each other, nor did the six least damaged accessions (Table 1 ). In the tests with $F$. occidentalis the mean damage scores ranged from 0.2 to 3.0. In this case within the six most damaged and the six least damaged accessions no significant differences were observed (Table 1).

\section{Comparison between tests}

We observed several different types of damage: leaf deformation, leaf curling, black spots, and silvering on the abaxial side of the leaf. There were no differences between the symptoms caused by $T$. parvispinus and
F. occidentalis in the leaf disc and detached leaf tests. The symptoms in the greenhouse for both T. parvispinus and $F$. occidentalis were also identical.

The observed symptoms differed between the tests with whole plants (greenhouse test) and those with leaf discs or detached leaves. In the greenhouse test the observed symptoms included silvering, curling and deformation of leaves, while in the leaf disc and detached leaf tests the symptoms were silvering and the presence of black spots. Heritability of damage scores in all screening methods was calculated and is shown in Table 2 . The heritability varied from 0.68 to 0.92 .

All correlations among the tests with T. parvispinus (greenhouse, leaf disc, detached leaf tests) were high $(0.77<\mathrm{R}<0.87)$ and significant $(P<0.001)$. The correlations were slightly lower between the tests with $F$. occidentalis (greenhouse, leaf disc, and detached leaf: $0.73<\mathrm{R}<0.77, P<0.01$ ) (Table 3). The correlation across species with the same test methods were also significantly correlated (Greenhouse: $\mathrm{R}=0.76, P<0.001$; leaf disc: $\mathrm{R}=0.71$, $P<0.001$; detached leaf: $\mathrm{R}=0.69, P<0.001)$.

Grouping accessions with a similar level of resistance

A hierarchical clustering of pepper accessions based on the test results with both thrips species produced dendrograms where all branchings have a high confidence level as based on bootstrap analysis (Fig. 2). Grouping the accessions into three clusters in both cases produced groups with low, intermediate and high resistance. All six accessions in the cluster resistant to $T$. parvispinus were also resistant to

Table 2 Genetic variance $\left(\sigma_{\mathrm{g}}^{2}\right)$, environment variance $\left(\sigma_{\mathrm{e}}^{2}\right)$, phenotypic variance $\left(\sigma_{\mathrm{p}}^{2}\right)$ and heritability $\left(\mathrm{h}^{2}\right)$ of score in screening methods of thrips resistance in pepper

\begin{tabular}{llllll}
\hline Thrips species & Test method & $\sigma_{\mathrm{g}}^{2}$ & $\sigma_{\mathrm{e}}^{2}$ & $\sigma_{\mathrm{p}}^{2}$ & $\mathrm{~h}^{2}$ \\
\hline T. parvispinus & Greenhouse & 0.947 & 0.082 & 1.030 & 0.92 \\
& Leaf disc & 0.835 & 0.189 & 1.024 & 0.82 \\
& Detached leaf & 0.964 & 0.184 & 1.149 & 0.85 \\
F. occidentalis & Greenhouse & 0.555 & 0.262 & 0.817 & 0.68 \\
& Leaf disc & 0.610 & 0.255 & 0.864 & 0.71 \\
& Detached leaf & 0.571 & 0.159 & 0.730 & 0.78 \\
\hline
\end{tabular}


Table 3 Spearman rank correlation coefficients and significance between damage score in screening methods of thrips resistance in pepper

\begin{tabular}{|c|c|c|c|c|c|c|}
\hline & & \multicolumn{2}{|c|}{ T. parvispinus } & \multicolumn{3}{|c|}{ F. occidentalis } \\
\hline & & Leaf disc & Detached leaf & Greenhouse & Leaf disc & Detached leaf \\
\hline \multirow[t]{3}{*}{ T. parvispinus } & Greenhouse & $0.77 * *$ & $0.80 * *$ & $0.76^{* *}$ & $0.65 *$ & $0.70 * *$ \\
\hline & Leaf disc & & $0.87 * *$ & $0.71 * *$ & $0.71 * *$ & $0.71 * *$ \\
\hline & Detached leaf & & & $0.73 * *$ & $0.70 * *$ & $0.69 * *$ \\
\hline \multirow[t]{2}{*}{ F. occidentalis } & Greenhouse & & & & $0.77 * *$ & $0.73 *$ \\
\hline & Leaf disc & & & & & $0.77 * *$ \\
\hline
\end{tabular}

* and ** indicate significance $P<0.01$ and $P<0.001$, respectively

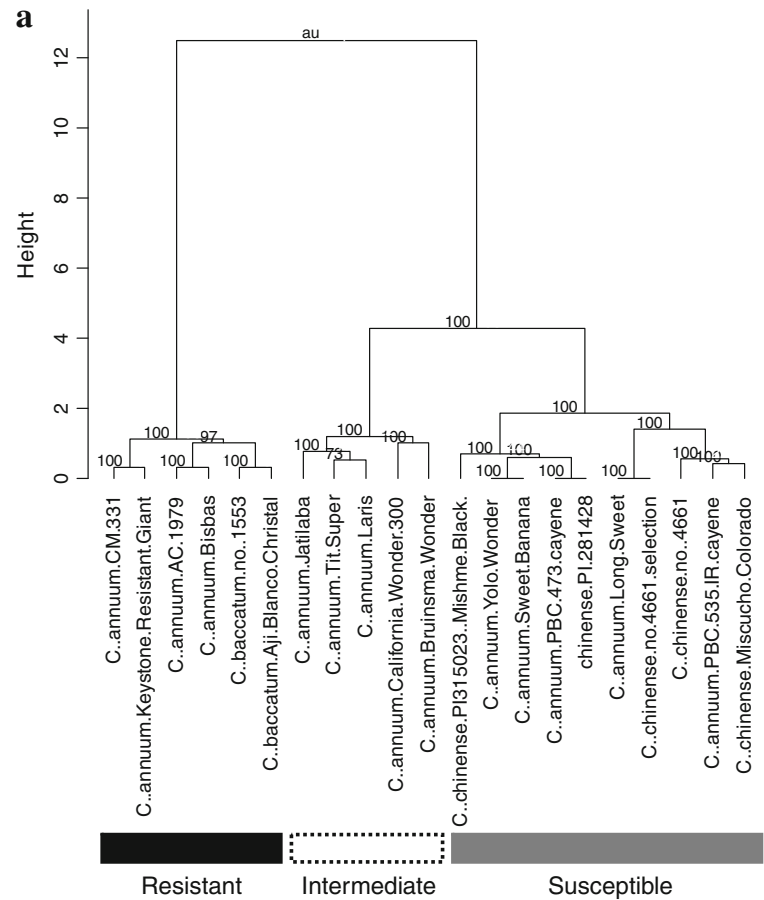

Fig. 2 Cluster analysis of pepper accessions based on their resistance level in three different tests against a Thrips parvispinus and b Frankliniella occidentalis. Values at branches are approximately unbiased (AU) $P$-values as

F. occidentalis, while only one (C. annuum PBC535 IR Cayenne) of the accessions that were resistant to $F$. occidentalis was susceptible to $T$. parvispinus. Conversely, all seven accessions in the cluster susceptible to $F$. occidentalis were also susceptible to $T$. parvispinus, and all 10 accessions susceptible to $T$. parvispinus were also susceptible or intermediate to $F$. occidentalis with the one exception mentioned above.

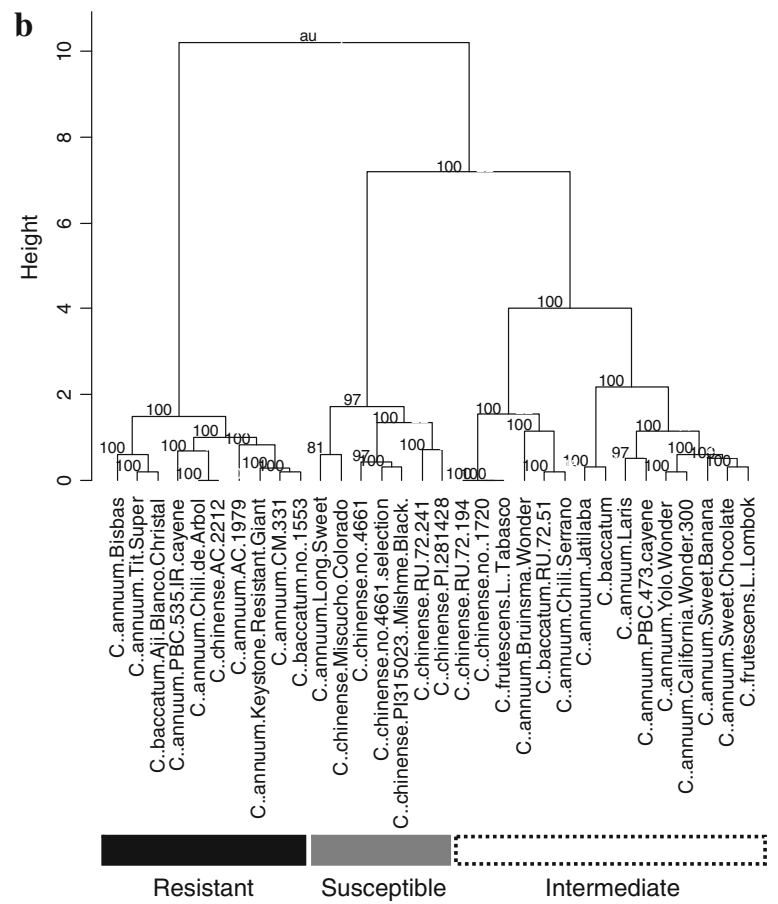

percentages (Suzuki and Shimodaira 2006). Although all branchings are strongly supported we have indicated three clusters in both dendrograms that represent resistant, intermediate and susceptible accessions

\section{Discussion}

Different resistance tests for thrips show highly similar results

High and very significant correlations between tests using one thrips species (Table 3 ) indicate that it is possible to use either the leaf disc or detached leaf test to screen pepper accessions for resistance against 
thrips, thus avoiding the problematic tests with whole plants. Compared to the greenhouse tests, leaf disc and detached leaf tests are relatively easy to conduct. A small climate room is sufficient to test many accessions. They also require less time: 2 days after inoculation the damage can be scored, compared with up to 7 weeks after transplantation for screenhouse and greenhouse tests. An additional advantage is that the plants from which leaves are tested remain uninfested by thrips. Finally, environmental factors during these tests can be better controlled than in greenhouse tests. The high heritability of thrips resistance (Table 2) in the leaf disc and detached leaf tests with both $T$. parvispinus and $F$. occidentalis indicate that the observed parameter in these tests (damage score) is strongly determined by genetic factors. The higher heritability in the greenhouse test with $T$. parvispinus in Indonesia compared with the other tests may be caused by the large amounts and uniform distribution of thrips in the test after a few weeks, and the fact that they developed under natural conditions from insects healthy enough to reach and enter the greenhouse on their own account. This contrasts with the smaller number of thrips (10) used in the laboratory tests, which were reared under artificial, perhaps non-optimal conditions and which were not selected for vigour.

It has been reported that more adult thrips were found on unwounded plants than on wounded plants (Delphia et al. 2007). However, we did not observe any difference in the type of symptoms on leaf discs versus whole leaves, nor in the general amount of damage. Furthermore the correlation between leaf disc and detached leaf tests was high and significant. As the leaf disc test allows a more standardized comparison than the detached leaf test and the leaf discs are more convenient to handle than whole leaves, the leaf disc test is the most suitable for assessing a large number of pepper accessions for resistance to thrips.

Different thrips species show similar results in pepper

We observed high correlations between the tests with both thrips species (Table 3). Furthermore, the damage caused by $F$. occidentalis and $T$. parvispinus was very similar in all the tests and on all accessions in our study. In the literature we found no reports of differences in damage caused by different thrips species on pepper. For onion, one report mentions that feeding injury caused by $F$. occidentalis is similar to that caused by $T$. tabaci Lindeman (Capinera 2001). These similarities in damage type and the high correlations between the amount of damage caused by different thrips species suggest that thrips resistance, at least in pepper, may not be very species-specific. We are aware of only one earlier report of resistance against multiple thrips species. (Babu et al. 2002) mentioned a high degree of resistance to Scirtothrips dorsalis and Polyphagotarsonemus latus in pepper accessions. Resistance to multiple thrips species is interesting as at least 16 species of thrips have been reported to occur on Capsicum (Capinera 2001; Talekar 1991). A widerange resistance would be very useful in the many regions where pepper is grown and attacked by multiple thrips species such as some Asian countries where both T. parvispinus (Reyes 1994) and F. occidentalis (Zhang et al. 2007) occur.

A large variation in resistance to thrips is found in pepper germplasm

We observed large differences in thrips damage between pepper accessions in our collection (Table 1). Earlier studies also reported a considerable variability within pepper germplasm for the response to thrips (Babu et al. 2002; Fery and Schalk 1991; Kumar et al. 1996). Unfortunately, we were not able to obtain the accessions studied by Kumar et al. (1996) and Babu et al. (2002), but some accessions used by Fery and Schalk (1991) were included in our experiments. Using $F$. occidentalis in a greenhouse test with damage scored on a scale from 1 to 5, Fery and Schalk (1991) rated Keystone Resistant Giant, Yolo Wonder, Sweet Banana, and California Wonder as 2.0, 2.1, 2.2 and 2.3 respectively. In our greenhouse test with $F$. occidentalis, these accessions were rated at $0.5,1.5,1.5$ and 1.5 on a scale from 0 to 3 (Table 1). Keystone Resistant Giant is the most resistant accession in Fery and Schalk's study (1991). Our study supports this by ranking Keystone Resistant Giant as resistant, and Yolo Wonder, Sweet Banana, and California Wonder as intermediate (Table 1, Fig. 2b). However, among our accessions we observed a wider range of damage scores and accessions more resistant than Keystone Resistant Giant. 
Six pepper accessions (C. апnиит AC 1979, C. annuum Bisbas, C. annuиm Keystone Resistant Giant, C. annuum CM 331, C. baccatum no. 1553, and C. baccatum Aji Blanco Christal) are identified as good sources for resistance against $T$. parvispinus and $F$. occidentalis. Six accessions are identified as susceptible accessions to both $T$. parvispinus and $F$. occidentalis $(C$. annuum Long Sweet, $C$. chinense Miscucho Colorado, C. chinense PI 281428, C. chinense no. 4661, C. chinense no. 4661 selection and $C$. chinense PI315023).

These result show that there is considerable variation for resistance to thrips in Capsicum that can be exploited in breeding programs and also further genetic studies related to thrips resistance in pepper.

Acknowledgments The research was financially supported by the Royal Netherlands Academy of Arts and Sciences in the framework of the Scientific Programme Indonesia-The Netherlands named IndoSol. We thank P.T. East West Seed Indonesia for providing the necessary facilities in conducting the Indonesian experiments.

Open Access This article is distributed under the terms of the Creative Commons Attribution Noncommercial License which permits any noncommercial use, distribution, and reproduction in any medium, provided the original author(s) and source are credited.

\section{References}

Babu B, Pandravada S, Reddy K, Varaprasad K, Sreekanth M (2002) Field screening of pepper germplasm for sources of resistance against leaf curl caused by thrips (Scirtothrips dorsalis Hood) and mites (Polyphagotarsonemus latus Banks). Indian J Plant Prot 30:7-12

Bielza P (2008) Insecticide resistance management strategies against the western flower thrips, Frankliniella occidentalis. Pest Manage Sci 64:1131-1138. doi:10.1002/Ps. 1620

Brodsgaard HF (1989) Frankliniella occidentalis-a new pest in Danish glasshouses. Tidsskr Planteavl 93:83-91

Capinera JL (2001) Order Thysanoptera-thrips. In: Capinera JL (ed) Handbook of vegetable pests. Elsevier Inc, pp. 535-550

Delphia CM, Mescher MC, De Moraes CM (2007) Induction of plant volatiles by herbivores with different feeding habits and the effects of induced defenses on host-plant selection by thrips. J Chem Ecol 33:997-1012. doi:10.1007/s10886007-9273-6

Dik A, Ceglarska E \& Ilovai Z (2000) Sweet pepper: development in plant pathology. In: Albajes R, Gullino M, van Lenteren J, Elad Y (eds) Integrated pest and disease management in greenhouse crops. Springer, Netherlands, pp. $473-485$
Fery R, Schalk J (1991) Resistance in pepper (Capsicum annuиm L.) to Western flower thrips [Frankliniella occidentalis (Pergande)]. HortScience 26:1073-1074

Grubben GJH, Denton OA (eds.) (2004) Plant resources of Tropical Africa 2

Herron GAJT (2005) Monitoring insecticide in Australian Frankliniella occidentalis Pergande (Thysanoptera: Thripidae) detects fipronil and spinosad resistance. Aust J Entomol 44:229-303

Herron G, James T (2005) Monitoring insecticide in Australian Frankliniella occidentalis Pergande (Thysanoptera: Thripidae) detects fipronil and spinosad resistance. Aust J Entomol 44:229-303

Jensen SE (2000) Insecticide resistance in the western flower thrips, Frankliniella occidentalis. Int Pest Manage Rev 5:131-146

Jones DR (2005) Plant viruses transmitted by thrips. Eur J Plant Pathol 113:119-157

Kogel WJ, Balkema-Boomstra A, Hoek MVd, Zijlstra S, Mollema C (1997) Resistance to western flower thrips in greenhouse cucumber: effect of leaf position and plant age on thrips reproduction. Euphytica 94:63-67

Koschier EH, De Kogel WJ, Visser JH (2000) Assessing the attractiveness of volatile plant compounds to western flower thrips Frankliniella occidentalis. J Chem Ecol 26: 2643-2655

Kumar NKK, Aradya M, Deshpande AA, Anand N, Ramachandar PR (1996) Initial screening of chili and sweet pepper germplasm for resistance to chili thrips, Scirtothrips dorsalis hood. Euphytica 89:319-324

Maris PC, Joosten NN, Goldbach RW, Peters D (2003) Restricted spread of tomato spotted wilt virus in thripsresistant pepper. Phytopathology 93:1223-1227

Murai T, Antoon JML (2001) Evaluation of an improved method for mass-rearing of thrips and thrips parasitoid. Entomologia Experimentalis et Applicata 113:149-155

Pineda A, Morales I, Marcos-Garcia MA, Fereres A (2007) Oviposition avoidance of parasitized aphid colonies by the syrphid predator Episyrphus balteatus mediated by different cues. Biol Control 42:274-280. doi:10.1016/j. biocontrol.2007.05.017

Prabaningrum L, Suhardjono YR (2007) Species identification of thrips (Tysanoptera) on sweet pepper (Capscium annuum var. grossum) in Bandung district, West Java Province, Indonesia. Jurnal Hortikultura 17:270-276

Reyes CP (1994) Thysanoptera (Hexapoda) of the Philipine Islands. Raffles Bull Zool 42:1-507

Rossel HW, Ferguson JM (1979) A new and economical screenhouse for viruses research in tropical climates. FAO Plant Prot Bull 27:74-76

Sharma HC, Pampapathy G, Dhillon MK, Ridsdill-Smith JT (2005) Detached leaf assay to screen for host plant resistance to Helicoverpa armigera. J Econ Entomol 98:568-576

Shipp J, Hao X, Papadopoulos A, Binns M (1998) Impact of western flower thrips (Thysanoptera: Thripidae) on growth, photosynthesis and productivity of greenhouse sweet pepper. Scientia Horticultura 78:87-102

Siemonsma JS, Piluek K (eds) (1994) Plant resources of South East Asia. No. 8. Vegetables. Prosea Foundation, Bogor, Indonesia 
Suzuki R, Shimodaira H (2006) Pvclust: an R package for assessing the uncertainty in hierarchical clustering. Bioinformatics Appl Note 22:1540-1542. doi:10.1093/bio informatics/btl117

Talekar N (1991) Thrips on pepper: AVRDC's research strategy. Regional Consulation Workshop, Bangkok, Thailand

Tommasini M, Maini S (1995) Frankliniella occidentalis and other thrips harmful to vegetable and ornamental crops in Europe. In: Loomans AJM, van Lenteren JC, Tommasini MG, Maini S, Ruidavets J (eds) Biological control of thrips pests, vol. 95, Wageningen University Papers, Wageningen, pp. 1-42

Ulman DE, Cho JJ, Mau RFL, Hunter WB, Westcot DM, Suter DM (1992) Thrips-tomato spotted wilt virus interactions: morphological, behavioural and cellular components influencing thrips transmission. Adv Dis Vector Res 9:196-240

Vos JGM, Frinking HD (1998) Pest and diseases of hot pepper (Capsicum sp.) in tropical lowlands of Java, Indonesia. J Plant Prot Trop 11:53-71
Ward JH (1963) Hierarchical grouping to optimize an objective function. J Am Stat Assoc 58:236-244

Weintraub PG (2007) Integrated control of pest in tropical and subtropical sweet pepper production. Pest Manag Sci 63:753-760

Welter SC, Rosenheim JA, Johnson MW, Mau RFL, Gusukumaminuto LR (1990) Effects of thrips-palmi and western flower thrips (Thysanoptera, Thripidae) on the yield, growth, and carbon allocation pattern in cucumbers. J Econ Entomol 83:2092-2101

Zhang ZJ, Wu Q, Li XF, Zhang YJ, Xu BY, Zhu GR (2007) Life history of western flower thrips, Frankliniella occidentalis (Thysanoptera, Thripidae), on five different vegetable leaves. J Appl Entomol 131:347-354. doi:10.1111/ j.1439-0418.2007.01186.x 